\title{
Total Signal Degradation of Polish 26-50 GHz Satellite Systems Due to Rain
}

\author{
Jacek Wilk-Jakubowski* \\ Kielce University of Technology, Faculty of Electrical Engineering, Automatic Control and Computer Science, \\ Department of Information Systems, Division of Computer Science, \\ 7 Tysiąclecia Państwa Polskiego Ave., 25-314 Kielce, Poland
}

Received: 7 February 2017

Accepted: 21 June 2017

\begin{abstract}
In practice, the propagation of electromagnetic waves is used in a large number of telecommunication wireless systems (e.g., satellites, radar, mobile phones, etc.). Since 2010 the Kielce University of Technology has been a member of a project focused on COST Action IC0802 - Propagation Tools and Data for Integrated Telecommunication, Navigation, and Earth Observation Systems. The main scientific objective was to analyze the impact of weather conditions on the quality of satellite transmissions. This article presents part of the results of that project for frequencies between $26 \mathrm{GHz}$ and $50 \mathrm{GHz}$. This information may be useful for ensuring the proper reception of microwave satellite signals and to minimize the risk of lack of communication due to adverse weather conditions.
\end{abstract}

Keywords: increase in noise due to precipitation, atmospheric attenuation, radio wave propagation, signal attenuation due to precipitation, total signal degradation

\section{Introduction}

Unfortunately, the characteristics of natural propagation media and their natural variability cannot be predicted. However, they can be inspected and reliably measured. This article includes studies of the effects of rain as one of the most important climatic factors [1-5]. In practice, these effects are of immense importance for links operating at frequencies above $20 \mathrm{GHz}$. General considerations are pertinent to propagation studies and are illustrated with examples, predominantly related to attenuation analysis.

This is very useful information for evaluating the quality of a satellite link and to estimate the maximum

*e-mail: j.wilk@tu.kielce.pl safe distance of margins of each link without interruptions in the selected geographical areas. For this reason all data could be accommodated in any technical solution by defining the specific parameters to ensure the links meet the main quality of signal criteria. Monitoring was carried out in an open field. Modeling remote sensing is useful for determining changes in rainfall statistics [6-10]. The collaboration between radio wave propagation experts could improve some of the provisions by assessing the physical fundamentals of radio wave propagation using experimental data and including results from new earth observation projects, as well as new numerical weather forecast models [11-14].

Measurements in the region of the city of Kielce, Poland, seem to be a good indication for system engineers and systems integrators who are responsible for link budget analyses, especially due to its central location 
in Poland, environment, land configuration, and the average value of rainfall intensity over 40 years. The results of an increase in noise, signal attenuation, and total signal degradation due to rain precipitation for the satellite signals in the area of Kielce, as a representative region in Poland, were received on the basis of the very detailed original meteorological parameters processed in statistical form.

As we can report from ITU-R Rec. P. 837-6, the contour maps show only an approximate $R_{0.01}$ parameter [15-16]. The rain rate $(\mathrm{mm} / \mathrm{h})$ exceeded $0.01 \%$ of the average year $\left(R_{0,01}\right)$ in Poland on the basis of the ITU-R contour map (one-minute integration time), and is also presented to compare the differences in noise increase, signal attenuation, and total signal degradation due to precipitation between data of the ITU-R Recommendation P.837-6 (ITU-R Rec. P. 837-6) and actual processed data derived over 40 years. This means approximately 53 minutes per year (52.56 minutes precisely) on the assumption that one year equals 365 days. This is connected with the availability of signals equaling on an average year $99.99 \%$ and in the worst month $99.948 \%$. We will take into account both the valuation of rain rate $(\mathrm{mm} / \mathrm{h})$ exceeding $0.01 \%$ of the average year $\left(R_{0.01}\right)$ estimated at $R_{0.01}=34.4 \mathrm{~mm} / \mathrm{h}$ in long-term perspective in Kielce as a representative region of Poland (40 years in this case), and $R_{0.01}=35 \mathrm{~mm} / \mathrm{h}$ on the basis of a contour map of the ITU-R for a location of Poland as a region of Europe.

\section{Material and Methods}

The used model uses bilinear interpolation to achieve an improved evaluation for the adjacent grids within the region of Kielce. The model of the ITU-R is based on the simulated movement of synthetic rain cells. The parameters were derived from local input data and from the European Centre of Medium-range Weather Forecast [15].

Data were originally collected from meteorological stations, quality checked, and further processed. The set of data collected by the European Space Agency (ESA) - a partner in COST ACTION IC 0802 in cooperation with the Institute of Meteorology and Water Management (National Research Institute, IMGW) in Warsaw, delivered information on the rain rate $(\mathrm{mm} / \mathrm{h})$ exceeding by $0.01 \%$ the average year in many regions in Poland. The data about rainfall intensity were generated at $1.125 \times 1.125^{\circ}$ longitude and latitude. Finally, results are presented in high resolution (two decimal places).

In practice, in many geographical locations in Poland the actual rainfall rate statistics obtained on the real measured values are smaller than the rainfall rate statistics reported by the ITU-R Rec. P. 837-6 contour map. Nevertheless, at certain locations (e.g., Gliwice, Katowice, Nowy Targ, Przemyśl, Rzeszów, Sandomierz, Sanok, Tarnobrzeg, Tarnów, Ustka, Władysławowo, Zakopane, and many others) the $R_{0.01}$ parameter is bigger than from ITU-R Rec. P. 837-6, as well in Kielce. These statistics are most crucial for specifying the maximum signal degradation due to rain.

\section{Results and Discussion}

\section{Experimental Results in Kielce from Laboratory Station}

Next to data specified in the ITU-R Rec. P. 837-6 $\left(R_{0.01}=35 \mathrm{~mm} / \mathrm{h}\right)$, we take into account the data collected by ESA. Thanks to this, the actual $R_{0.01}$ parameter derived from 40 years was determined in Kielce $\left(R_{0.01}=34.4 \mathrm{~mm} / \mathrm{h}\right)$.

Tables 1 and 2 show the precise data for frequencies between 26 and $50 \mathrm{GHz}$ for horizontally and vertically polarized radio waves, respectively. The article includes

Table 1. $W_{s z}, L_{d}$, and $D N D(\mathrm{~dB})$ vs. frequency $(\mathrm{GHz})$ for $R_{0.01}=34.4 \mathrm{~mm} / \mathrm{h}$ (pol. H).

\begin{tabular}{|c|c|c|c|}
\hline$f(\mathrm{GHz})$ & $L_{d_{0,01}}(\mathrm{~dB})$ & $W_{s z}(\mathrm{~dB})$ & $D N D(\mathrm{~dB})$ \\
\hline 26 & 24.94 & 5.00 & 29.94 \\
\hline 27 & 26.43 & 5.00 & 31.43 \\
\hline 28 & 27.91 & 5.00 & 32.91 \\
\hline 29 & 29.39 & 5.00 & 34.39 \\
\hline 30 & 30.86 & 5.00 & 35.87 \\
\hline 31 & 32.33 & 5.00 & 37.33 \\
\hline 32 & 33.78 & 5.00 & 38.79 \\
\hline 33 & 35.22 & 5.01 & 40.23 \\
\hline 34 & 36.65 & 5.01 & 41.65 \\
\hline 35 & 38.06 & 5.01 & 43.06 \\
\hline 36 & 39.45 & 5.01 & 44.46 \\
\hline 37 & 40.82 & 5.01 & 45.83 \\
\hline 38 & 42.17 & 5.01 & 47.18 \\
\hline 39 & 43.51 & 5.01 & 48.51 \\
\hline 40 & 44.82 & 5.01 & 49.82 \\
\hline 41 & 46.10 & 5.01 & 51.11 \\
\hline 42 & 47.37 & 5.01 & 52.37 \\
\hline 43 & 48.61 & 5.01 & 53.61 \\
\hline 44 & 49.82 & 5.01 & 54.83 \\
\hline 45 & 51.02 & 5.01 & 56.02 \\
\hline 46 & 52.19 & 5.01 & 57.19 \\
\hline 47 & 53.33 & 5.01 & 58.34 \\
\hline 48 & 54.46 & 5.01 & 59.46 \\
\hline 49 & 55.56 & 5.01 & 60.56 \\
\hline 50 & 56.63 & 5.01 & 61.64 \\
\hline
\end{tabular}


Table 2. $W, L$, and $D N D(\mathrm{~dB})$ vs. frequency $(\mathrm{GHz})$ for $R_{0.01}=34.4 \mathrm{~mm} / \mathrm{h}$ (pol. V).

\begin{tabular}{|c|c|c|c|}
\hline$f(\mathrm{GHz})$ & $L_{d_{0.01}}(\mathrm{~dB})$ & $W_{s z}(\mathrm{~dB})$ & $D N D(\mathrm{~dB})$ \\
\hline 26 & 22.72 & 4.99 & 27.71 \\
\hline 27 & 24.13 & 4.99 & 29.12 \\
\hline 28 & 25.55 & 5.00 & 30.55 \\
\hline 29 & 26.97 & 5.00 & 31.97 \\
\hline 30 & 28.40 & 5.00 & 33.40 \\
\hline 31 & 29.83 & 5.00 & 34.83 \\
\hline 32 & 31.25 & 5.00 & 36.25 \\
\hline 33 & 32.66 & 5.00 & 37.66 \\
\hline 34 & 34.06 & 5.00 & 39.07 \\
\hline 35 & 35.45 & 5.01 & 40.46 \\
\hline 36 & 36.83 & 5.01 & 41.83 \\
\hline 37 & 38.19 & 5.01 & 43.19 \\
\hline 38 & 39.53 & 5.01 & 44.53 \\
\hline 39 & 40.85 & 5.01 & 45.86 \\
\hline 40 & 42.15 & 5.01 & 47.16 \\
\hline 41 & 43.44 & 5.01 & 48.44 \\
\hline 42 & 44.70 & 5.01 & 49.71 \\
\hline 43 & 45.94 & 5.01 & 50.95 \\
\hline 44 & 47.16 & 5.01 & 52.17 \\
\hline 45 & 48.36 & 5.01 & 53.37 \\
\hline 46 & 49.54 & 5.01 & 54.55 \\
\hline 47 & 50.70 & 5.01 & 55.70 \\
\hline 48 & 51.83 & 5.01 & 56.84 \\
\hline 49 & 52.94 & 5.01 & 57.95 \\
\hline 50 & 54.04 & 5.01 & 59.04 \\
\hline
\end{tabular}

the consideration of signal attenuation $L_{d}$, noise increase $W_{s z}$, and total signal degradation $D N D$ due to precipitation. It should be remembered that total signal degradation $D N D$ is the sum of signal attenuation $L_{d}$ and noise increase $W_{\mathrm{sz}}$ due to rain.

Tables 1 and 2 summarize the impact of rain on the three coefficients $\left(L_{d}, W_{s z}, D N D\right)$. These show how the statistical data theoretically introduced in the beginning can be applied to provide information about rainfall intensity $R_{0.01}$ in Poland. This $R_{0.01}$ parameter can be useful for calculating signal quality in practice.

Figs 1 and 2 illustrate the results of measurements for horizontally and vertically polarized radio waves, respectively. As we can observe, the signal attenuation of horizontally polarized radio waves is greater than the signal attenuation of vertically polarized radio waves in the frequency range covered. In addition, the increase in the signal frequency results in the gradual increase in the

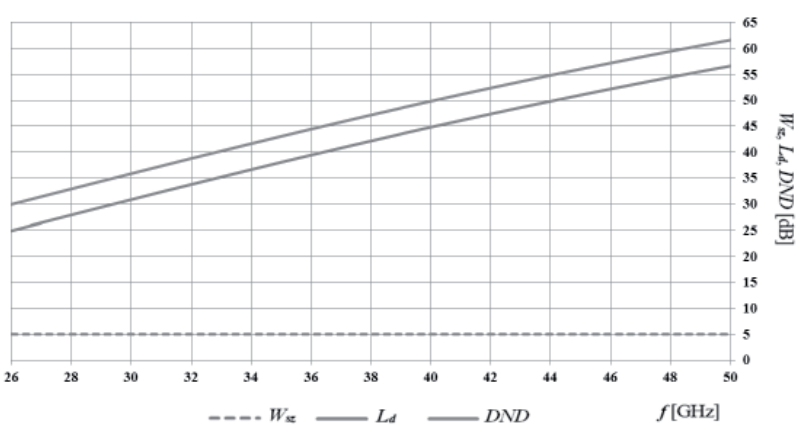

Fig. 1. $W_{s z}, L_{d}$, and $D N D(\mathrm{~dB})$ vs. frequency $(\mathrm{GHz})$ for $R_{0.01}=34.4$ $\mathrm{mm} / \mathrm{h}$ (pol. H).

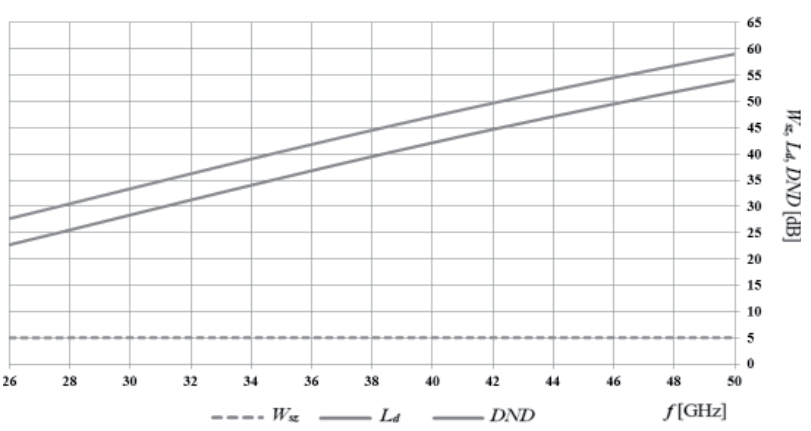

Fig. 2. $W_{s z}, L_{d}$, and $D N D(\mathrm{~dB})$ vs. frequency $(\mathrm{GHz})$ for $R_{0.01}=34.4$ $\mathrm{mm} / \mathrm{h}$ (pol. V).

difference in signal attenuation $L_{d}$ between horizontally and vertically polarized radio waves. This difference does not exceed $2.67 \mathrm{~dB}$ and has a minimum value of $2.22 \mathrm{~dB}$ for a $26 \mathrm{GHz}$ frequency.

Moreover, we can see that the difference between total signal degradation $D N D$ of horizontally and vertically polarized radio waves does not exceed $2.5 \mathrm{~dB}$ for the signal frequencies below $31 \mathrm{GHz}$, and $2.6 \mathrm{~dB}$ for the signal frequencies below $35 \mathrm{GHz}$. The maximum difference of total signal degradation $D N D$ is almost equal to $2.7 \mathrm{~dB}$. The noise increase due to precipitation in the frequency range $26-50 \mathrm{GHz}$ is roughly equal to $0 \mathrm{~dB}$ (the maximum difference equals $0.01 \mathrm{~dB}$ ).

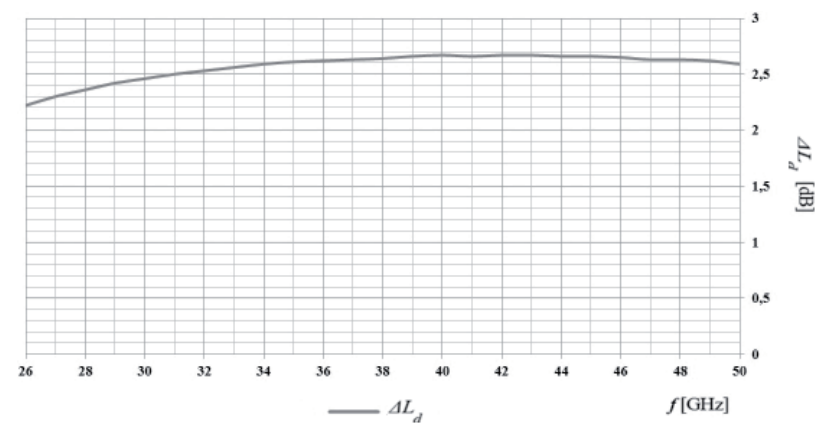

Fig. 3. Increase in $\Delta L_{d}(\mathrm{~dB})$ vs. frequency $(\mathrm{GHz})$ for $R_{0.01}=34.4$ $\mathrm{mm} / \mathrm{h}($ pol. H-V). 
Fig. 3 presents the difference of attenuation $L_{d}$ between horizontally and vertically polarized radio waves $\Delta L_{d}$ in the range $26-50 \mathrm{GHz}$. The maximum difference of signal attenuation approximately equals $2.67 \mathrm{~dB}$ (see Fig. 3).

There is still a tendency that with the increase in the signal frequency the difference between signal attenuation $\Delta L_{d}$ for horizontally and vertically polarized radio waves gradually increases. All of the data collected could be used to estimate the impact of rainfall intensity, polarization, and radio wave frequency with a step of $1 \mathrm{GHz}$ on the quality of received satellite signals.

\section{Experimental Results in Kielce from the ITU-R Contour Map}

In this part of article, the results of measurements are to be compiled for each type of polarization on the basis of contour map of the ITU-R to compare the values with

Table 3. $W_{s z}, L_{d}, D N D[\mathrm{~dB}]$ vs frequency $[\mathrm{GHz}]$ for $R_{0.01}=35$ $\mathrm{mm} / \mathrm{h}$ (pol. H).

\begin{tabular}{|c|c|c|c|}
\hline$f(\mathrm{GHz})$ & $L_{d_{0,01}}(\mathrm{~dB})$ & $W_{s z}(\mathrm{~dB})$ & $D N D(\mathrm{~dB})$ \\
\hline 26 & 25.23 & 5.00 & 30.22 \\
\hline 27 & 26.73 & 5.00 & 31.72 \\
\hline 28 & 28.22 & 5.00 & 33.22 \\
\hline 29 & 29.72 & 5.00 & 34.72 \\
\hline 30 & 31.20 & 5.00 & 36.21 \\
\hline 31 & 32.68 & 5.00 & 37.69 \\
\hline 32 & 34.15 & 5.00 & 39.15 \\
\hline 33 & 35.60 & 5.01 & 40.61 \\
\hline 34 & 37.04 & 5.01 & 42.05 \\
\hline 35 & 38.46 & 5.01 & 43.47 \\
\hline 36 & 39.87 & 5.01 & 44.87 \\
\hline 37 & 41.25 & 5.01 & 46.26 \\
\hline 38 & 42.62 & 5.01 & 47.62 \\
\hline 39 & 43.96 & 5.01 & 48.96 \\
\hline 40 & 45.28 & 5.01 & 50.28 \\
\hline 41 & 46.58 & 5.01 & 51.58 \\
\hline 42 & 47.85 & 5.01 & 52.86 \\
\hline 43 & 49.10 & 5.01 & 54.11 \\
\hline 44 & 50.33 & 5.01 & 55.33 \\
\hline 45 & 51.53 & 5.01 & 56.54 \\
\hline 46 & 52.71 & 5.01 & 57.72 \\
\hline 47 & 53.87 & 5.01 & 58.87 \\
\hline 48 & 55.00 & 5.01 & 60.00 \\
\hline 49 & 56.10 & 5.01 & 61.11 \\
\hline 50 & 57.19 & 5.01 & 62.19 \\
\hline
\end{tabular}

the results of rain intensity measurements. Consequently, it will be possible to compare both data in the frequency range covered.

Because of the $R_{0.01}$ parameter reported of the ITU-R Rec. P. 837-6 has the approximate value, the results even if $I T U-R$ Rec. P. 837 is up-to-date are only approximate [15]. The results of the signal attenuation $L_{d}$, noise increase $W_{s z}$ and total signal degradation $D N D$ (the sum of these components) for horizontally polarized radio waves are shown in Table 3.

The analogous results of the signal attenuation $L_{d}$, noise increase $W_{s z}$ and total signal degradation $D N D$ due to precipitation for vertically polarized radio waves are presented in Table 4 below.

In any case, the difference in $R_{0.01}$ parameter in Kielce city between actual data from laboratory station and contour map of the $I T U-R$ is equal to $0,6 \mathrm{~mm} / \mathrm{h}$. As might be expected, the increase in the signal frequency leads

Table 4. $W_{s z}, L_{d}, D N D[\mathrm{~dB}]$ vs frequency $[\mathrm{GHz}]$ for $R_{0.01}=35$ $\mathrm{mm} / \mathrm{h}$ (pol. V).

\begin{tabular}{|c|c|c|c|}
\hline$f(\mathrm{GHz})$ & $L_{d_{0.01}}(\mathrm{~dB})$ & $W_{s z}(\mathrm{~dB})$ & $D N D(\mathrm{~dB})$ \\
\hline 26 & 22.98 & 4.99 & 27.97 \\
\hline 27 & 24.40 & 5.00 & 29.39 \\
\hline 28 & 25.83 & 5.00 & 30.83 \\
\hline 29 & 27.27 & 5.00 & 32.27 \\
\hline 30 & 28.71 & 5.00 & 33.71 \\
\hline 31 & 30.15 & 5.00 & 35.15 \\
\hline 32 & 31.58 & 5.00 & 36.59 \\
\hline 33 & 33.01 & 5.00 & 38.01 \\
\hline 34 & 34.42 & 5.00 & 39.43 \\
\hline 35 & 35.83 & 5.01 & 40.83 \\
\hline 36 & 37.21 & 5.01 & 42.22 \\
\hline 37 & 38.58 & 5.01 & 43.59 \\
\hline 38 & 39.94 & 5.01 & 44.94 \\
\hline 39 & 41.27 & 5.01 & 46.28 \\
\hline 40 & 42.59 & 5.01 & 47.59 \\
\hline 41 & 43.88 & 5.01 & 48.88 \\
\hline 42 & 45.15 & 5.01 & 50.16 \\
\hline 43 & 46.40 & 5.01 & 51.41 \\
\hline 44 & 47.63 & 5.01 & 52.64 \\
\hline 45 & 48.84 & 5.01 & 53.85 \\
\hline 46 & 50.03 & 5.01 & 55.04 \\
\hline 47 & 51.19 & 5.01 & 56.20 \\
\hline 48 & 52.34 & 5.01 & 57.34 \\
\hline 49 & 53.46 & 5.01 & 58.47 \\
\hline 50 & 54.56 & 5.01 & 59.57 \\
\hline
\end{tabular}


to the increase in the difference in signal attenuation $L_{d}$ between horizontally and vertically polarized radio waves and consequently to the increase in the total signal degradation between horizontally and vertically polarized radio waves. It does not exceed $2.5 \mathrm{~dB}$ for the signal frequencies below $30 \mathrm{GHz}$ and $2.69 \mathrm{~dB}$ for the signal frequencies below $40 \mathrm{GHz}$. The maximum difference of total signal degradation $D N D$ is equal to $2.7 \mathrm{~dB}$. The noise increase due to precipitation in the frequency range between $26-50 \mathrm{GHz}$ is almost equal to $0 \mathrm{~dB}$ (the maximum difference equals $0.01 \mathrm{~dB}$ ) as for the measures referred to the $R_{0.01}$ parameter equals $34.4 \mathrm{~mm} / \mathrm{h}$.

Unsurprisingly, we can see that the signal attenuation of both type of polarization for the rainfall intensity $R_{0.01}=35 \mathrm{~mm} / \mathrm{h}$ is greater than the signal attenuation received on the basis of actual data from measuring position $\left(R_{0.01}=34.4 \mathrm{~mm} / \mathrm{h}\right)$ for horizontally and vertically polarized radio waves, respectively.

Figs 4 and 5 illustrate the results of measurements for the rainfall intensity $R_{0.01}=35 \mathrm{~mm} / \mathrm{h}$ obtained on the basis of contour map of $I T U-R$ for horizontally and vertically polarized radio waves, respectively.

Fig. 5 presents the equivalent diagram for vertically polarized radio waves.

As we can observe, the results of signal attenuation $L_{d}$ and signal degradation due to rain precipitation $D N D$ for the $R_{001}=35 \mathrm{~mm} / \mathrm{h}$ parameter (received on the basis

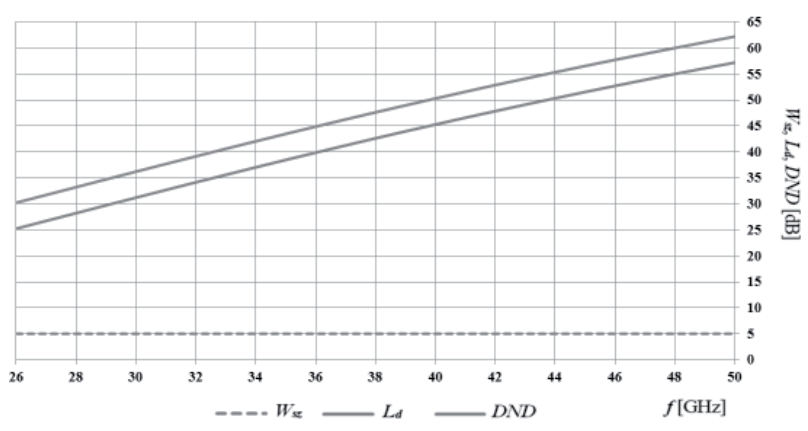

Fig. 4. $W_{s z}, L_{d}, D N D[\mathrm{~dB}]$ vs frequency $[\mathrm{GHz}]$ for $R_{0.01}=35 \mathrm{~mm} / \mathrm{h}$ (pol. H)

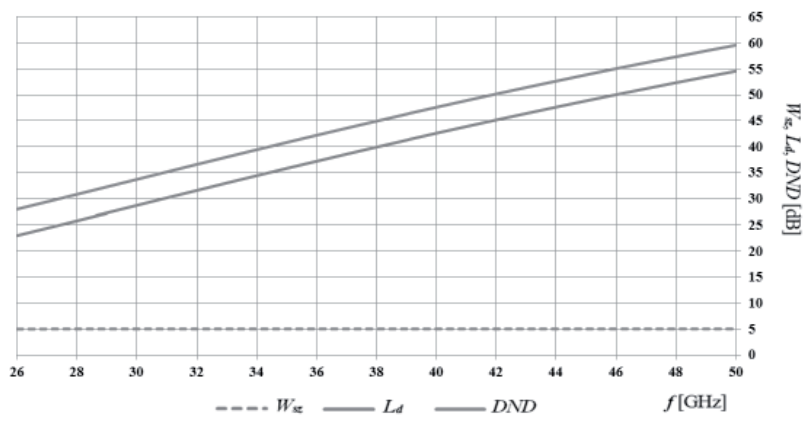

Fig. $5 . W_{s z}, L_{d}, D N D[\mathrm{~dB}]$ vs frequency [GHz] for $R_{0.01}=35 \mathrm{~mm} / \mathrm{h}$ (pol. V). of contour map of ITU-R Rec. P. 837-6) are greater than the results of signal attenuation $L_{d}$ and signal degradation due to rain precipitation $D N D$ for $R_{0.01}=34.4 \mathrm{~mm} / \mathrm{h}$ parameter (achieved owing to the data from measuring position). With the reliable and accurate scientific knowledge in long-term perspective (40 years in this case), we can improve link budgets of satellite links due to the precise forecasts of signal attenuation $L_{d}$, noise increase $W_{s z}$ and total signal degradation due to rain precipitation $D N D$.

\section{Conclusions}

In practice cutting-edge researches are increasingly being conducted at the interface between many countries to collect detailed information as possible. All of the data presented in this article may be used to estimate the impact of the rainfall intensity, polarization and radio wave frequency on the quality of satellite signals in the frequency range between 26-50 GHz in Poland. Moreover, we can use the tabular data for horizontally and vertically polarized radio waves in this frequency range to achieve the forecast of noise increase, signal attenuation and total signal degradation due to precipitation with use of polynomial regression models, too. These are also critically important in future to minimize the risk of lack of communication or interruption of the connection, as well as the communication due to weather conditions endangering the satisfactory condition of the signal. Another application could be determine the link budget analysis in a function of many parameters.

In practice, satellite equipment may have an unique flexibility system for a control of signal quality and adopt some operational parameters of transmitting systems, such as transmitting power to the formed quality of signal criteria. Therefore depending on the weather conditions, the system switches automatically between several possible signal powers to optimize transmission quality. So, we can application of presented data to dynamical changes in parameters of transmission in compensation systems.

Ongoing research could be used in future work to analyse the propagation of microwave satellite signal above $50 \mathrm{GHz}$ or to combine the signal by transmultiplexer [20]. In future, it aims to make analysis of absorption [21], as well as determine the link budget and among others the impact of various mechanisms affecting the propagation of radio waves to achieve the ready regression models [22].

\section{References}

1. CETIN M., ADIGUZEL F., KAYA O., SAHAP A. Mapping of bioclimatic comfort for potential planning using GIS in Aydin. Environment, Development and Sustainability, in press, DOI: 10.1007/s10668-016-9885-5, 1-15, 2016. Available online: http://link.sprin ger.com/article/10.1007/ s10668-016-9885-5 (accessed on 09.04.2017). 
2. CETIN M. Determining the bioclimatic comfort in Kastamonu City. Environmental Monitoring and Assessment, 187 (10), 640, 2015. Available online: http:// link.springer.com/article/10.1007\%2Fs10661-015-4861-3 (accessed on 09.04.2017).

3. CETIN M. Determination of bioclimatic comfort areas in landscape planning: A case study of Cide Coastline. Turkish Journal of Agriculture-Food Science and Technology, 4 (9), $800,2016$.

4. CETIN M., TOPAY M., KAYA LG., YILMAZ B. Efficiency of bioclimatic comfort in landscape planning process: case of Kutahya. Turkish Journal of Forestry, 1 (1), 83, 2010.

5. CETIN M., SEVIK H. Assessing Potential Areas of Ecotourism through a Case Study in Ilgaz Mountain National Park, $1^{\text {st }}$ ed.; Butowski L., InTech: Rijeka, Croatia, 81, 2016. Available online: http://www.intechopen.com/ books/tourism-from-empirical-research-towards-practicalapplication/assessing-potential-areas-of-ecotourismthrough-a-case-study-in-ilgaz-mountain-national-park (accessed on 09.04.2017).

6. CETIN M., SEVIK H. Evaluating the recreation potential of Ilgaz Mountain National Park in Turkey. Environmental Monitoring and Assessment, 188 (1), 52. Available online: $\quad$ http://link.springer.com/article/10.1007\%2 Fs10661-015-5064-7 (accessed on 07.02.2017).

7. CETIN M. Using GIS analysis to assess urban green space in terms of accessibility: case study in Kutahya. International Journal of Sustainable Development \& World Ecology, 22 (5), 420, 2015. Available online: http://www. tandfonline.com/doi/full/ $\quad$ 10.1080/13504509.2015.1061066 (accessed on 07.02.2017).

8. CETIN M. Sustainability of urban coastal area management: a case study on Cide. Journal of Sustainable Forestry, 35 (7), 527, 2016. Available online: http://dx.doi.org/10.1080/10 549811.2016.1228072 (accessed on 07.02.2017)

9. CETIN M. Evaluation of the sustainable tourism potential of a protected area for landscape planning: a case study of the ancient city of Pompeipolis in Kastamonu. International Journal of Sustainable Development \& World Ecology, 22 (6), 490, 2015. Available online: http://www.tandfonline. com/doi/abs/10.1080/13504509.2015. 1081651?src=recsys\& journalCode $=\mathrm{tsdw} 20$ (accessed on 07.02.2017).

10. CETIN M. Consideration of permeable pavement in Landscape Architecture. Journal of Environmental Protection and Ecology, 16 (1), 385, 2015. Available online: https://docs.google.com/a/jepe-journal.info/viewer? $\mathrm{a}=\mathrm{v} \&$ pid=sites\&srcid=amVwZS1qb3 VybmFsLmluZm98amV wZS1qb3VybmFsfGd4OjNmY2FkYzYzN2Y1MWN1YjM (accessed on 07.02.2017).

11. BENARROCH A., GARCÍA-DEL-PINO P., GARCÍARUBIA J. M., RIERA J. M. Derivation of rain attenuation from experimental measurements of drop size and velocity distributions. COST IC0802 (MCM3). Available online: http://www.tesa.prd.fr/ cost/input_documents. pdf (accessed on 22.04.2017).

12. BOULANGER X., CASTANET L., JEANNIN N., LACOSTE F. Study and modelling of tropospheric attenuation for land mobile satellite system operating at $\mathrm{Ku}$ and $\mathrm{Ka}$ band. COST IC0802 (MCM2). Available online: http://www.tesa.prd.fr/cost/input_documents. pdf (accessed on 22.04.2017).

13. WILK J.Ł. Total signal degradation due to rain precipitation in the troposphere in the area of Kielce city. Scientific Journal. Telecommunications and Electronics, 262 (17), 5, 2013.

14. WILK-JAKUBOWSKI G. The influence of ICT on the modern societies. The Role of Informatics In Economic and Social Sciences. Innovations and Interdisciplinary Implications, 1, 11, 2011 [In Polish].

15. ITU-R. REC. P. 837-6. Characteristics of precipitation for propagation modeling. Available online: http://www.itu.int/ rec/R-REC-P.837-6-201202-I/en (accessed on 18.04.2017).

16. ITU-R. RADIO REGULATIONS. Edition of 2016. Available online: http://www.itu.int/en/publications/ ITU-R/Pages/default.aspx (accessed on 18.04.2017).

17. EUROPEAN COOPERATION IN THE FIELD OF SCIENTIFIC AND TECHNICAL RESEARCH - COST. Memorandum of Understanding for the implementation of a European Concerted Research Action designated as COST Action IC0802: Propagation tools and data for integrated Telecommunication, Navigation and Earth Observation systems. Available online: http://w3.cost.eu/fileadmin/ domain files/ICT/Action_IC0802/ mou/IC0802-e.pdf (accessed on 22.04.2017).

18. EUROPEAN COOPERATION IN THE FIELD OF SCIENTIFIC AND TECHNICAL RESEARCH - COST. Final evaluation Report: Propagation Tools and Data for Integrated Telecommunication, Navigation and Earth Observation Systems. Available online: http://w3.cost.eu/ fileadmin/domain_files/ICT/Action_IC0802/final_report/ final report-IC0802.pdf (accessed on 18.04.2017).

19. WILK J.Ł. Współpraca naukowa w ramach Projektu Europejskiego COST IC0802. Wschód i Zachód w wymiarze globalnym. Doświadczenia z przeszłości a perspektywy na przyszłość, 1st ed.; Wydawnictwo Stowarzyszenia Współpracy Polska-Wschód. Oddział Świętokrzyski: Kielce, Poland, 163, 2012 [In Polish].

20. CIOSMAK J. An algorithm of determining non-separable two-dimensional filer arrays for transmultiplexion systems. Przegląd Elektrotechniczny, 11 (87), 217, 2011.

21. MARCINIAK M., NOSICH A.I., ZINENKO T.L. Accurate Analysis of Light Scattering and Absorption by an Infinite Flat Grating of Thin Silver Nanostrips in Free Space Using the Method of Analytical Regularization. IEEE Journal of Selected Topics in Quantum Electronics, 3 (19), 2013. Available online: http://ieeexplore.ieee.org/ document $/ 6353499 /$ ?part $=1$ (accessed on 22.04.2017).

22. MAREK M. The use of econometric model of the classical linear regression function for quantitative analysis in economics. The Role of Informatics In Economic and Social Sciences. Innovations and Interdisciplinary Implications, 2 , 214-220, 2013 [In Polish]. 